of my walking to the sofa now! Isn't that an improvement?") and each summer found her better, and each winter less ill than formerly. ${ }^{5}$ Finally, with her marriage in September 1846 she escaped to a warmer climate with a less polluted atmosphere and her bronchitis did not trouble her for some years.

One legacy of Elizabeth's illness remained: her so called addiction to opium. It was prescribed by her doctors for her cough and insomnia. She never became an addict and was able to control her dependence-for example, abstaining during her pregnancies. Her own estimates of her opium consumption may well have been greatly exaggerated, for later in Italy her small son drank her recently purchased supply of special elixir and suffered no effects.

\section{Setbacks in London and Paris}

After her marriage Elizabeth's health continued to improve and despite a serious miscarriage in 1850 she was able to climb the steps to the top of Milan Cathedral in the spring of 1851. But her summer in London that year started her cough again, and succeeding visits in 1852, 1855, and 1856 each made their inroads as did the winters in Paris in 1851 and 1855 . Her bronchial attacks returned and by 1857 she was an invalid again. In paralytic scoliosis respiratory and cardiac failures usually do not appear until the fourth or fifth decade. That they did not appear in Mrs
Browning until the sixth decade would imply a less severe deformity. Once failure has become manifest the clinical course is usually rapidly downhill, characterised by repeated episodes of cardiac failure, often precipitated by pulmonary infection. ${ }^{14}$ For Mrs Browning it was a remorseless decline to her death in June 1861 from heart failure following congestion of the right lung.

1 Barrett E, McCarthy BP, ed. Elizabeth Barrett to Mr Boyd. The unpublished letters of Elizabeth Barrett Browning to Hugh Stuart Bovd. London: John Murray, 1955.

2 Ritchie A. Elizabeth Barrett Browning. In: The dictionary of national hiograph (up to 1900). Vol 3. Oxford: Oxford University Press, 1921:78-82.

3 Landis P, Freeman R, eds. The letters of the Brownings to George Barret Appendix 2. Illinois: University of Illinois Press, 1958.

Ward M. Robert Browning and his world: the private face $(1812-1861)$. London: Cassell and Co, 1968

5 Barrett E. In: Miller B, ed. Elizabeth Barrett to Miss Mitford. The unpublished letters. London: John Murray, 1954.

6 Moulton-Barrett A. The Barretts of Wimpole Street. Jamaica Daily (Gleaner. 1938 June 13.

Hewlett D. Elizabeth Barrett Browning. London: Cassell and Co, 1953.

8 Roaf R. Scoliosis. Edinburgh: Livingstone, 1966.

9 James JIP, Zorab PA, Wynne-Davies R. Paralytic scoliosis. In: Scoliosis. 2nd ed. London: Churchill Livingstone, 1976.

10 Heydon PN, Kelley P, eds. Elizabeth Barretl Browning letters to Mrs Ogilyy aith recollections by Mrs Ogilvy. London: John Murray, 1974.

11 Shneerson JM. Deformities of the thoracic cage. In: Emerson P, ed. Thoraci medicine. London: Butterworth and Co. 1981:358-65.

12 Barrett E. In: Bevridge E, ed. The Barretts at Hope End. (The early diary of Elizabeth Barrett Browning). London: John Murray, 1974.

13 Hayter A. Mrs Browning: A poet's work and its setting. London: Faber and Faber, 1962.

14 Fraser RG, Paré JAP. Diseases of the diaphragm and chest wall. In: Diagnosis of diseases of the chest. Vol 3. 2nd ed. Philadelphia: W B Saunders Co. 1979:1899-902.
Renal Unit, St Thomas's Hospital, London SE1 7EH N T Richards, MRCP, honorary registrar in nephrology

M McCann, SRN, sister

A Samson, SRN, sister

A Johnson, chief technician

Renal Unit, St

Bartholomew's Hospital, London EC1

J Tattersall, MRCP, honorary registrar in nephrology

T Mathias, SRN, sister

Correspondence to: $\mathrm{Dr}$ Richards.

BrMed f 1989;298:443-5

\title{
Dialysis for acute renal failure due to crush injuries after the Armenian earthquake
}

\author{
N T Richards, J Tattersall, M McCann, A Samson, T Mathias, A Johnson
}

On 7 December 1988 an earthquake measuring more than 9 on the Richter scale struck northern Armenia, killing thousands of people and injuring many more. The exact number killed will never be known, but official estimates range between 26000 and 50000 and local estimates between 120000 and 190000 . In the first few days after the disaster it became apparent that many people were developing acute renal failure secondary to the crush syndrome.

\section{Acute renal failure due to the crush syndrome}

Acute renal failure induced by myoglobin after trauma (the crush syndrome) was first described by Bywaters and Beall ${ }^{1}$ and Beall $e t a l^{2}$ in patients with injuries related to war. Since then there have been reports of the condition during wars ${ }^{3}$ and after earthquakes. ${ }^{4}$ Non-traumatic acute renal failure induced by myoglobin is also well documented in conditions such as drug abuse (heroin and barbiturates), alcoholism, and polymyositis. ${ }^{5}$ The condition is characterised by oliguric acute renal failure of rapid onset. The main biochemical abnormalities are severe hyperkalaemia and hyperphosphataemia with associated severe hypocalcaemia. Muscle enzyme levels are extremely high and free myoglobin is present in urine and plasma. Patients die of hyperkalaemia unless they are treated rapidly.

Treatment of the condition after a natural disaster such as an earthquake poses particular problems. Firstly, because of the difficulties in finding and extracting the victims many of them will die of hyperkalaemia before they can be treated. Secondly, all patients develop acute renal failure at the same time, thus overwhelming the available services.

\section{Appropriate aid}

Negotiations among the British government, the Royal Air Force mobile dialysis team, and officials from the Soviet Embassy failed to produce an agreeable formula for an official aid package. In general, the Soviet officials seemed to want equipment alone rather than equipment and staff combined. Several renal units in Britain offered help in providing dialysis machines and staff. The portable Redy (Sorb system) seemed the most appropriate equipment to take as it operates with small volumes of unprepared water. ${ }^{6}$ Peritoneal dialysis and continuous haemofiltration were considered but rejected because of the large amounts of sterile replacement fluid required by both. The renal unit at St Thomas's Hospital is particularly experienced in using the Redy because of the requirement to have an emergency plan in case of flooding from the Thames.

The initiative from St Thomas's and St Bartholomew's Hospitals was organised through Aid Armenia, the official relief charity. The team, consisting of a doctor, two nurses, and a technician from St Thomas's and a doctor and a nurse from St Bartholomew's was assembled on the Monday morning with equipment sufficient for 100 dialyses. Dialysis machines provided by several units, including those at Derriford Hospital, Plymouth, Bristol Royal Infirmary, and Addenbrooke's, St Helier, and St Bartholomew's Hospitals, were flown out by Soviet cargo plane on the Monday 
night. The team with the equipment from St Thomas's Hospital left on the Tuesday morning by Aeroflot from Heathrow, eventually arriving in Yerevan in a Soviet military cargo plane on the Wednesday.

\section{Haemodialysis in Yerevan}

The Yerevan branch of the All Union Scientific Surgical Centre had been designated as the centre for treating acute renal failure. We were taken there on the Thursday and after being interviewed by Doctor Professor Alexander L Mikaeylan, the director of the institute, to establish who we were we started work.

The hospital had admitted 800 adults after the disaster; 460 had the crush syndrome, 185 of them having acute renal failure. Sixty five (mainly men) of the patients with acute renal failure were sent to Moscow with 200 children who also had acute renal failure. Of the remainder, 24 were dialysed by the military forces and 40 were treated conservatively. This left 56 patients requiring dialysis.

In the hospital there were three nephrology teams: the local Armenian unit augmented by nephrologists from Moscow, us, and a West German unit, which had arrived on the Sunday after the disaster in its own Jumbo jet with enough equipment for two renal units. Initially we worked in a converted $x$ ray department with just sufficient space for five dialysis stations. We were responsible for treating 12 patients. Later we transferred to a ward where all the severely infected patients were, and here we treated three patients. The horrendous wounds and the malodour of rampant infection made this a particularly harrowing experience for all concerned. The West Germans, who worked in a converted operating theatre, a store room, and the intensive care unit, had about 12 dialysis stations and treated around 20 patients. The Armenians and Russians worked in the 12 bedded long term dialysis unit and treated the remainder as well as their own patients with chronic renal failure. At our busiest more than 70 patients were dialysed daily in the hospital, making it temporarily one of the largest units in the world. Cooperation among the three different teams was excellent at all times.

The patients treated by us consisted of 12 women and three men who were aged between 9 and 65 and had various injuries. All 15 patients had severely crushed limbs; four had had a leg amputated above the knee and one had lost both legs. Two women had

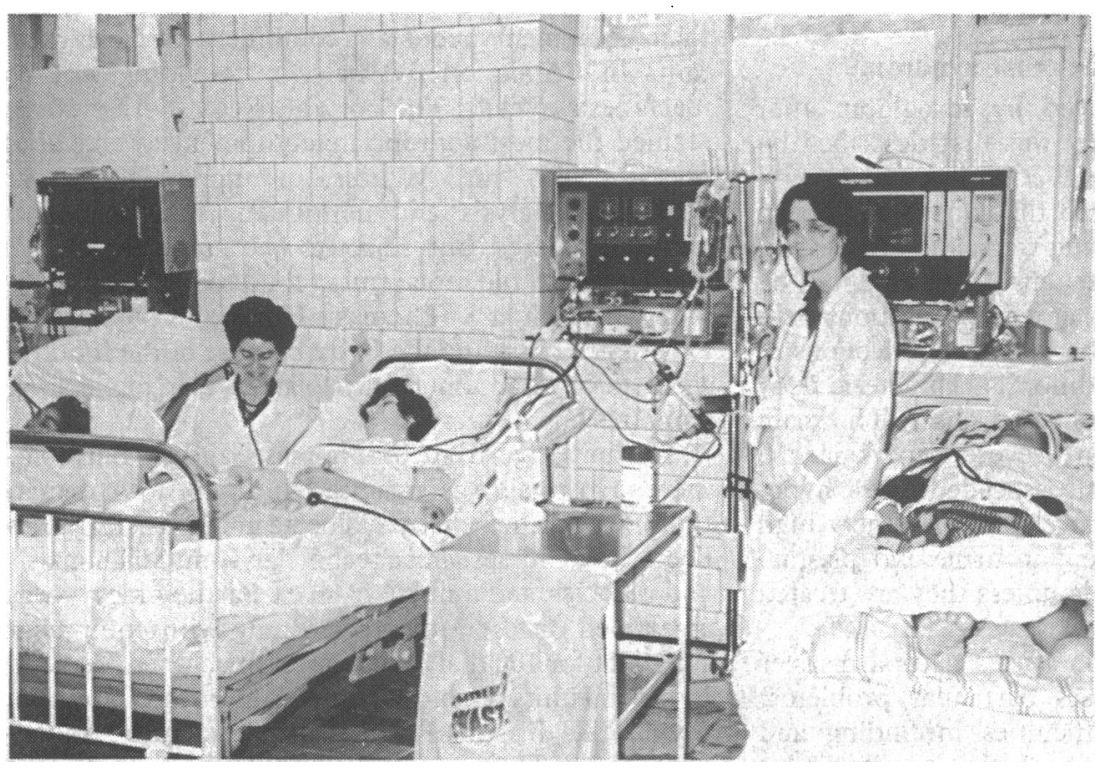

British dialysis unit in Armenia spinal transections in the lumbar region and two had had spontaneous abortions at more than seven months' gestation (the babies dying in both cases). Only two had other abdominal injuries (one small bowel resection, one ruptured bladder) and none had major head or chest trauma. Three of the patients whom we treated had not been dialysed before we arrived (seven days after the earthquake) yet had survived, which is contrary to experience from similar disasters elsewhere. It seems from this that patients with major trauma to the head, chest, or abdomen did not survive long enough to reach hospital.

All patients treated in the first few days had had wrist arteriovenous shunts inserted, but their supply had run out and many had clotted. In those who had no vascular access or a clotted shunt double lumen catheters were used (internal jugular eight, subclavian four). All patients were dialysed daily for three to four hours. In general, dialysis was tolerated extremely well both by patients who had previously been dialysed and by those in whom we performed the first dialysis. This includes one patient who had a plasma urea concentration of $140 \mathrm{mmol} / \mathrm{l}$ and a plasma calcium concentration of $0.43 \mathrm{mmol} / \mathrm{l}$ before her first dialysis. The main clinical problems encountered were sepsis, anaemia (most patients had haemoglobin concentrations between 40 to $60 \mathrm{~g} / \mathrm{l}$ ), disseminated intravascular coagulation (two patients), and allergy to cephalosporin (one patient). All patients were receiving ceftazidime in large doses, but some patients remained septicaemic despite this and three developed a generalised, erythematous, intensely pruritic rash. We treated the sepsis with vancomycin and gentamicin and asked for the ceftazidime to be stopped. There was a plentiful supply of blood and plasma which arrived in $250 \mathrm{ml}$ reusable glass bottles. Blood was, however, crossmatched at the bedside and six patients (not treated by us) who had recovered renal function had severe transfusion reactions. All six became oliguric again and two died.

When we left on Christmas Eve, one patient had died of uncontrolled sepsis, nine were no longer dependent on dialysis, two were passing urine, and the remaining three were oliguric. By 14 January at least nine had left hospital.

Before the disaster the local dialysis unit's equipment was, by the Armenians' own admission, tired and at least 20 years old. When departing, both we and the West German team left all the equipment behind, and this was used to re-equip the Armenian unit. The local dialysis staff were taught how to use it by us and the West Germans.

In all we performed 57 dialyses. The estimated total value of the British nephrology aid was about $£ 160000$, which implies a cost of $£ 2800$ per dialysis. A lot of equipment, however, had been donated both by renal units around the country and by several companies, including Organon. Teknika, Kimal Scientific Products, Cobe Laboratories, Macarthy's Laboratories, Gambro, and Unicare Medical Services. The final cost will, however, still be many thousands of pounds. The giving of aid in this case, however, has done more than save lives that would otherwise have been lost: it has shown that the artificial boundaries of political ideology can be removed and that cooperation between East and West is possible to the mutual benefit of all concerned.

Throughout our stay in Armenia we were treated extremely cordially by everyone who met us. The language barrier was not a problem as there were many interpreters and several of the local doctors spoke good English. There seemed to be no shortage of food, which was provided in large quantities daily. We later learnt that most of it was provided by patients' relatives. 


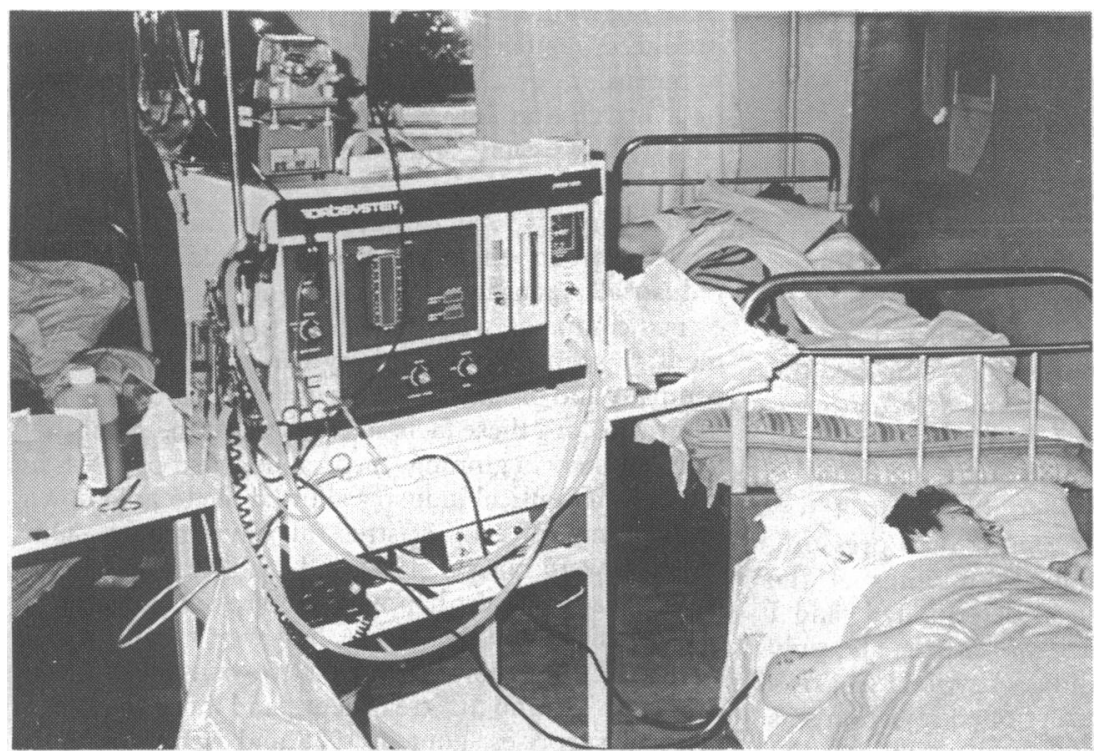

Bedside dialysis for patient with severe wound infection

\section{Lessons learnt}

Several lessons may be learnt from this experience. Firstly, the appropriate aid must arrive rapidly at the right place to lessen natural triage. Obviously after a major disaster in which the local medical services have either been destroyed or overwhelmed replacing or augmenting them rapidly will help reduce both mortality and morbidity. The incidence of acute renal failure after crush injuries may be dramatically reduced by urgent replacement of intravenous fluid. Patients who do develop acute renal failure will die of hyperkalaemia within one to two days if dialysis is not started. Such a rapid response can be achieved only by a permanent relief team available to depart at a few hours' notice. This is amply shown by the fact that the West German team arrived three days after the disaster compared with our arrival time four days later (a week after the event).

Secondly, any aid of this type must be fully self supporting. All equipment required to perform a task, both disposables and machinery, must be taken with technical support to ensure that the machinery continues to work. The team should have several forms of transport at their disposal, depending on the geography of the disaster area. This ensures that the staff and the equipment arrive together without affecting local transport facilities, which may already be overwhelmed. Back up and good communications are vital both to resupply the team and to maintain morale. Previous knowledge of local conditions is invaluable, particularly for dialysis as the availability of a power supply and a source of water will determine what method of treatment is appropriate.

Finally, but most importantly, you must remember at all times that you are guests in someone else's country.

\footnotetext{
Bywaters EGL, Beall D. Crush injuries with impairment of renal function. $\mathrm{Br}$ Med F 1941; ;:427-32.

2 Beall D, Bywaters EGL, Belsey RHR, Miles JAR. A case of crush injury with renal failure. $B r M e d ~ \mathcal{~} 1941 ; i: 432-4$.

Michaelson M, Taitelman U, Bshouty Z, Bar-Joseph G, Bursztein S. Crush syndrome: experience from the Lebanon War. Isr f Med Sci 1984;20:305-7. Santangelo ML, Usberti M, Di Salvo E. A study of the pathology of crush syndrome. Surg Gynecol Obstet 1982;154:372-4.

Glassock R. Haematuria and pigmenturia. In: Massry SG, Glassock R, eds. Textbook of nephrology Baltimore: Williams and Wilkins, 1984;4:20-3

6 Wing AJ, Parsons FM, Drukker W. Dialysate regeneration. In: Drukker W, Wing AJ, Parsons FM, Drukker W. Dialysate regeneration. In: Drukker W, Parsons FM, Maher JF, eds. Replacement of renal function by dialysis.
Boston: Nijhoff, 1983:323-40.
}

(Accepted 6 February 1989)

\section{Pills: a personal history of hypertension}

\section{B D Mills}

My hypertension was discovered when I was 21 , in 1950 , just before the era of antihypertensive drugs. Thus my adult life has coincided with the evolution of the treatment of hypertension, and both the disease and its treatment have had a major impact on my professional and family life. Having retired at 57 after an exacting career in engineering and industrial management, I firmly believe that success in the treatment of chronic diseases can be achieved with active self management based on some understanding of both the disease and the treatment.

\section{Early life}

I spent an outdoor childhood in North Queensland playing tennis, cricket, and rugby as often as possible. School ensured that one contracted the full gamut of childhood diseases, my only distinction being the inclusion of jaundice in my portfolio. From a secondary school with a strong tradition of sporting achievement I went to Queensland University, where I graduated in electrical engineering in 1949 and in science in 1950.

The Australian Department of Supply announced in mid-1950 its intention to award several scholarships allowing successful candidates an opportunity to study for a higher degree in the United Kingdom. At the end of the selection process I was awarded one "subject to a satisfactory medical examination." I had not the slightest doubt that I would sail through any medical with flying colours. In the event, excessive albumin was detected in a urine sample and my systolic blood pressure was said to be highly labile and above $150 \mathrm{~mm} \mathrm{Hg}$ (at age 21). The department decided that I was a poor risk (as the quid pro quo of the three year scholarship was a requirement to work for the department for five years afterwards), and my award was withdrawn.

Disappointed at my failure to achieve the scholarship, I consulted a Brisbane specialist in the hope that treatment might correct the condition. The outcome was shattering: a more relaxed lifestyle was the only recommendation. "Slow down-give up sport-don't run for the tram, there is always another one-take life at a slower pace." To someone used to leading a full academic and athletic life this advice was distinctly unpalatable. Second opinions from medical friends supported these recommendations, so I gave up all sport and attempted to slow down.

Despite this unwelcome development I decided to go to Britain to gain technical experience and to see as much of Europe as possible; 1951 passed quickly with an interesting job and touristic excursions at weekends. By spring 1952 life seemed a little dull without sporting challenge, and as I felt well I decided to take up social tennis. I enjoyed a marvellous summer of club tennis until palpitations developed on courtmild at first, but by autumn too fierce to be disregarded. An evening visit to a local doctor led to an 